\title{
Comparative analysis of delayed alternation learning in cats, mice, and guinea pigs
}

\author{
JOSEF KESSLER, HANS J. MARKOWITSCH, WOLFGANG GULDIN, \\ RUDOLF RIESS, MONIKA PRITZEL, MARIA STREICHER, and MARCUS KERRIOU \\ University of Konstanz, D-7750 Konstanz, Federal Republic of Germany
}

\begin{abstract}
The performance of cats, guinea pigs, and mice in a delayed alternation paradigm was compared both during initial learning and following a 10-day retention interval. The testing situation (a modified T-maze), the length of the delay period $(10 \mathrm{sec})$, and the amount of training per session and per week were kept identical for all three species. The results indicated that (1) animals of all three species acquired the task within similar time spans, (2) a considerable variance was apparent in the performance of individual animals independent of their species, and (3) guinea pigs, as a group, appeared to need a somewhat longer time to acquire delayed alternation than did mice and cats. Relearning of the task following the 10-day interval seemed to follow similar laws in all three species.
\end{abstract}

Delayed reaction-type tasks are among the oldest learning problems in comparative animal psychology (Hunter, 1920; Yarbrough, 1917). They were "considered at that time to be the first real test of "higherorder capacities' [and] as a method for differentiating species along a phylogenetic continuum", (Fletcher, 1965, p. 129). Though both of these views have been challenged severely in recent times (Hodos, 1970; Hodos \& Campbell, 1969; Lockard, 1971; Warren, 1972, 1973), it still appears worthwhile to compare the behavior of different species in a controlled environment, both from a psychological view (Bitterman, 1975; Brookshire, 1970; Denny \& Ratner, 1970; Warren, 1973) and from a more neurophysiological point of view (Herschel, 1972; Kummer, 1961; Riddell, Corl, Bennett, \& Reimers, 1974).

The spatial delayed-alternation task appears to be a favorable test of animal learning and memory across species. Performance in this task is influenced only minimally by perceptual factors or by preferences in sensory modalities which might differ among species (cf. Nigrosh, Slotnick, \& Nevin, 1975). On the other hand, the necessity to remember, over the delayed period, either which path had been followed in the previous trial or which path had to be chosen in the next trial, or both, was thought to yield clearcut inferences about differences in short-term memory capacity across species (cf. reviews of Fletcher, 1965; Weiskrantz, 1968). The limitations of such a

We thank E. Webster and F. M. Wharton for improving the language. G. Ehret and B. Haack deserve thanks for discussions on the ecological and ethological aspects of the behavior of the three species studied. The research was supported in part by Grant Ma 795 of the Deutsche Forschungsgemeinschaft. Reprint requests may be sent to $H$. J. Markowitsch, Department of Psychology, University of Konstanz, P.O. Box 5560, D-7750 Konstanz, West Germany. view have been discussed extensively by Weiskrantz (1968) and can be inferred in part from a short description of the following studies in which the performance of different species in delayed-reactiontype tasks has been compared.

Livesey, for example, compared the performance of rats, rabbits, cats, rhesus monkeys, and children in a delayed double-alternation task and observed that, depending on the measure used, rather different sequences in performance ranks among these species were found (Livesey, 1964, 1965, 1969, 1970; Livesey \& Little, 1971). When the rate of acquisition was used for comparing the performance of species, "rhesus monkeys took about as long to learn a double alternation sequence as did rats [and] fouryear-old children took about as long as raccoons" (Livesey \& Little, 1971, p. 36). On the other hand, unlike cats and raccoons, rhesus monkeys and children were able to extend the sequence to 8 and 12 responses. Similar observations were also summarized in a review by Warren (1965); he described a hierarchy in the rate of learning double-delayed alternation from monkeys to cats to rabbits to raccoons (from worst performance to best). Contrary to these findings, Leonard, Schneider, and Gross (1966) reported that a comparison of 'level of performance on Miles' variable-delay, delayed-response procedure arranged the species ... in the following order (from best performance to worst): rhesus monkey, squirrel monkey, marmoset, cat, and tree shrew" (p. 504).

Procedural variations in the type of delayedreaction tasks used across species may therefore-at least in part-account for the interspecies variations observed. How large the differences in acquisition of delayed alternation can be, even within a given species, has been shown for cats by Markowitsch and Pritzel (1978) in a testing situation which minimized spatial 
and kinesthetic cues (box with two levers) compared with a situation using a large $T$-maze. Such differences have also been found with monkeys using the WGTA, a primate restraining chair, and a maze (Stamm, 1970).

We report here an interspecies comparison of the acquisition of delayed alternation in which (a) the maze testing situation (aside from a proportional reduction in the size of the maze between species), (b) the length of the delay period, and (c) the amount of training (number of trials per session and days of training per week) were identical for all species studied.

The species selected belong to the orders carnivora (cats) and rodentia (mice, guinea pigs). Mice and guinea pigs are members of two different suborders (myomorpha, caviomorpha). All three species employed are domestic forms, and all can be characterized as macrosmates. Compared with mice and guinea pigs, cats may depend less on olfactory than on auditory and visual information (Beadle, 1977; Leicht, 1979; Maier \& Maier, 1970).

While cats are remote from both other species in taxonomic status, they are closer to mice than to guinea pigs in specific adaptations to the environment. Cats and mice appear to be sexually monomorphic, are altricial, have a large litter size, and are both carnivorous and herbivorous, whereas guinea pigs appear to be sexually dimorphic, show a precocial development, have a small litter size, and prefer a vegetarian diet (Hale, 1962). A peculiarity of guinea pigs, as compared with cats and mice, is that they do not use their forefeet when eating (Leicht, 1979).

Other ecological and ethological factors, however, reveal clear differences in the behaviors of rodents and carnivores. We shall refer only to examples that might be of relevance to the present investigation. Exploratory behavior and curiosity are less pronounced in mice and guinea pigs than in cats (Harper, 1976; Maier \& Maier, 1970). A likely reason for this may be that "active exploratory behavior is most advantageous to animals that do not have natural predators" (Maier \& Maier, 1970, p. 339).

Though both of our rodent species demonstrate less curiosity than do cats, Glickman and Hartz (1964) have observed that, among seven rodent species tested for exploratory behavior, white mice and guinea pigs were on the upper and lower ends of the interspecies distribution under free-testing conditions. This result is in accordance with the high degree of shyness and fear that characterizes the behavior of guinea pigs in novel situations (Harper, 1976; Jonson, Lyle, Edwards, \& Penny, 1975). In spite of the fact that mice and guinea pigs show less active exploratory behavior than do cats, both of these rodent species learn the complexities of their environments by acquiring stable and repetitively expressed motoric patterns (Kunkel \& Kunkel, 1964; Maier \& Maier, 1970).
From the sum of the above-mentioned specific adaptations of each of the three species, it follows that all three manifest advantages and disadvantages with respect to delayed-alternation learning. Whether the sum of advantages and disadvantages is balanced across species remains to be shown.

\section{METHOD}

\section{Subjects}

The subjects were 18 female white mice (Balb C), 19 male tricolored guinea pigs (Cavia porcellus), and 19 male and 10 female cats. At the start of the testing, the mice were about 70 days old (weight: $20-26 \mathrm{~g}$ ), the guinea pigs were $4-5$ months old (weight: $480-730 \mathrm{~g}$ ), and the cats were 8 to 36 months old (weight: $1.8-4.3 \mathrm{~kg}$ ). All animals were housed in individual cages and maintained on standard diets of commercial food. The animals were not deprived, but received their daily food only following testing.

\section{Apparatus}

A modified T-maze (illustrated in Markowitsch \& Pritzel, 1978, and in Markowitsch, Pritzel, Kessler, Guldin, \& Freeman, 1980) was used for all three species. The basic structure consisted of a wooden T-maze, with a combined start- and goalbox, and a central running alley. The two "T-arms" led back to the starting point via two right-angled alleys. The starting point therefore included a centered hole through which the reward could be presented on a movable tray. The starting alley could be closed of by a manually operated guillotine door. Similarly, two movable side doors prevented the animals from entering a side alley during the delay time. The alleyways were covered with plywood and Plexiglas. For mice, the maze was $45 \mathrm{~cm}$ long, $45 \mathrm{~cm}$ wide, and $10 \mathrm{~cm}$ high; for guinea pigs, the respective measurements were 145,115 , and $20 \mathrm{~cm}$; for cats, they were 250,220 , and $43 \mathrm{~cm}$.

\section{Procedure}

All animals were trained 5 or 6 days a week at approximately the same hour each day. Initially, the animals explored the maze for up to $20 \mathrm{~min}$. Small pieces of reward were placed irregularly in all sections of the alleys. These consisted of rolled oats for the mice, fresh dandelion for the guinea pigs, and liver for the cats. By gradually reducing the number of places that had rewards, the animals were guided to follow a path leading directly from the startbox to the reward tray. Delay times were measured with a stopwatch. The mice and guinea pigs were trained by one experimenter, and the cats were trained by two experimenters. In the final shaping phase, reward was presented only if the animal alternated correctly. At this stage, the formal delayed-alternation training, consisting of 21 trials per session, was started. At the beginning of the first trial of each session the animal was placed in the combined start- and goalbox and the guillotine door was raised. The animal chose one of the arms of the T-maze and was rewarded after it returned to the goalbox. This trial was not counted. A 10 -sec delay period was interposed between the time the animal reached the goalbox and the time the guillotine door was opened for the second trial. This and all subsequent trials followed the same sequence as Trial 1. If the animal made an error, that is, entered the same arm of the T-maze repeatedly, reward was omitted. Also, for incorrect trials, the delay period lasted $10 \mathrm{sec}$. After one or more trials with errors, the animal was rewarded only when it changed to the alternative arm of the T-maze. Criterion for all three species was 3 consecutive days of at least $85 \%$ correct performance. For the mice, however, the total number of errors over all three sessions was limited to six.

After reaching criterion during initial acquisition, the animals were given a rest period of 10 days. Retention of the task was then measured, using the identical criterion as in the acquisition phase. 
Animals that did not reach criterion within a predetermined period were discarded from further study. These periods were 500 trials for cats and 600 trials for guinea pigs and mice. Five of the 19 guinea pigs had to be discarded, whereas only four mice and only one cat had to be rejected during the training phase.

\section{RESULTS}

For all comparisons, nonparametric statistical tests were used (Marascuilo \& McSweeney, 1977; Siegel, 1956). As measures of the central tendencies of a distribution, medians were computed throughout. Significance values are given for two-tailed testing. Learning curves were computer-generated and smoothed as suggested by Reinsch (1967).

To obtain a quantitative measure of the consistency with which the animals gained in performance to criterion, a so-called index of consistency was computed (Levine, Hull, Buchwald, \& Villablanca, 1978, p. 562f), with the modification that nonparametric statistics were used to establish this index.

Computations of saving scores differ from the formula usually used (e.g., Iversen \& Weiskrantz, 1967) by dividing the number of errors by the number of trials. We think that this correction-saving score $=\{$ [number of errors (acquisition) $/$ number of trials (acquisition)] - [number of errors (relearning)/ number of trials (relearning) $]\} /\{$ [number of errors (acquisition)/number of trials (acquisition)] + [number of errors (relearning)/number of trials (relearning)]\}more adequately reflects what should be expressed by a saving score.

\section{Shaping Phase}

In comparison with cats and mice, the guinea pigs needed about twice as much shaping to reach the beginning of formal delayed-alternation training.

\section{Delayed Alternation}

Acquisition and relearning. The cats needed 3-24 sessions (median: 5 sessions), the guinea pigs 6-29 sessions (median: 15), and the mice 4-24 sessions (median: 12) to gain criterion. Retention phases lasted 3-13 sessions for the cats (median: 4), 3-9 sessions for guinea pigs (median: 4.5 ), and 3-21 sessions for the mice (median: 4.5).

Figure 1 shows both initial learning curves and retention curves for all three species, while Figure 2 demonstrates the overlap between species measured in sessions to reach criterion both for the acquisition of delayed alternation and for relearning following a 10-day retention interval.

The outcomes of all statistical comparisons that

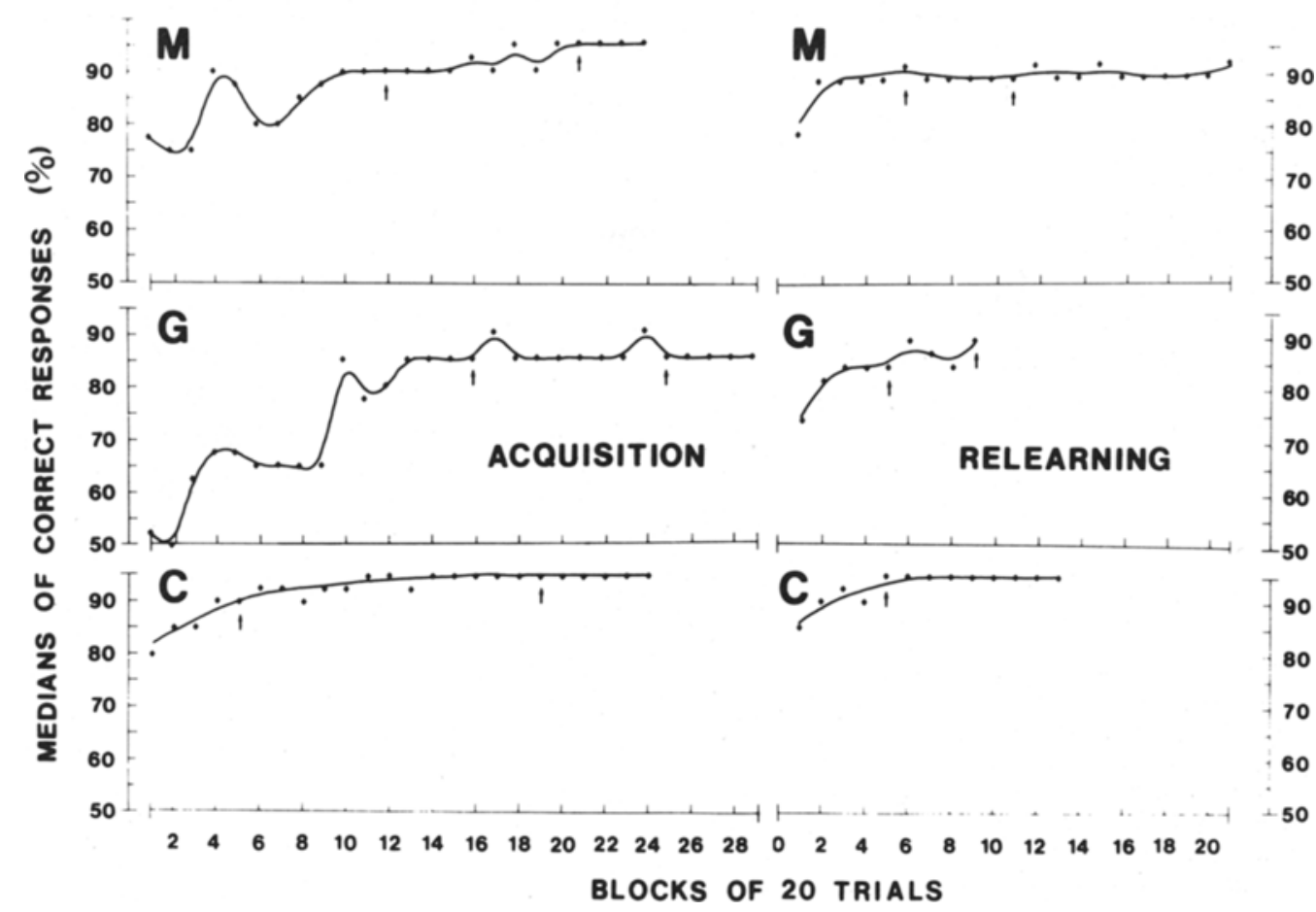

Figure 1. Learning curves of mice (M), guinea pigs (G), and cats (C) in acquisition and in relearning stages of delayed alternation. As individual animals reached criterion in different numbers of sessions, the following computations were completed: for each animal that had reached criterion, an average value, namely the median of the performance rate during the last three sessions, was established and included in the computations of all following sessions. This measure appears to be more appropriate for describing the performance of each species than are Vincent curves (cf. Hilgard, 1938). The first arrow in each curve indicates the point at which at least half of the animals had reached criterion; the second arrow marks the point at which all but one of the animals had reached criterion. This second arrow is omitted in the relearning phase of the cats because here the last two animals reached criterion simultaneously. The number of animals participating in each of the sessions can be found in Figure 4 . 


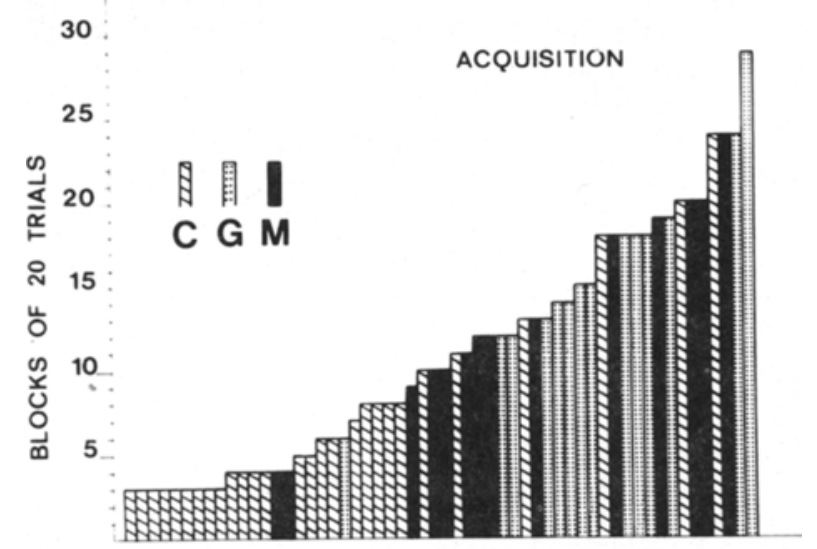

RANK POSITIONS OF ANIMALS

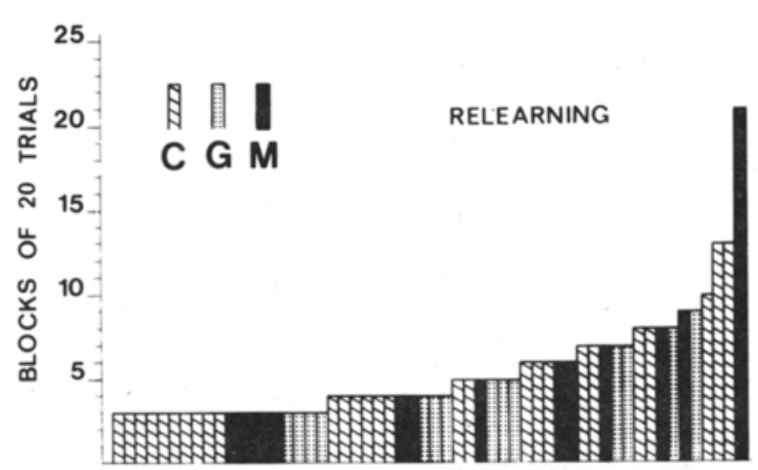

RANK POSITIONS OF ANIMALS

Figure 2. Rank positions of cats (C), guinea pigs (G), and mice $(M)$ in acquisition and in relearning of delayed alternation.

produced significant results are summarized in Table 1. The performance of the cats during delayed alternation acquisition was superior to that of the other two species, when comparing both the number of trials (comparison 1, Table 1) and the number of errors/ trials to criterion (comparison 2). Guinea pigs ranked lowest in both of these measures, which may, in part, be due to the differences in the initial level of correct responses between species. Here the guinea pigs started at chance level, while cats and mice made $75 \%$ correct responses from the start (comparison 3 ).

During relearning, the initial level of correct responses was similar for all three species. By number of trials to criterion during the relearning phase, there were no differences among the three species, while by the measure of errors/trials needed to relearn delayed alternation, guinea pigs were inferior (comparison 4).

Cats and guinea pigs manifested consistent performance increments during delayed alternation acquisition, while mice appeared rather inconsistent (comparison 5). On the other hand, more similar measurements were observed during relearning among the three species (comparison 6).

Correlations of trials to criterion during acquisition with trials to criterion during relearning were nonsignificant for all three species, though they approached significance in the cats $(.05<\mathrm{p}<.01)$. This also reflected in a further correlation, namely that between trials to criterion during acquisition and saving score. This measure revealed a significant correlation within the cat group (comparison 7).

Error analysis. Figures 3 and 4 demonstrate the percentages of median values of initial and of perseverative errors (cf. Lawicka, 1959; Lawicka \& Konorski, 1961) of the three species during acquisition and during relearning.

In Figure 3, for each cat that had reached criterion, an average value, consisting of the median performance rate during the last three sessions, was established and included in the computation of all following sessions. A similar computation of learning curves had been used by Markowitsch and Pritzel (1978), except that they had used means instead of medians (cf. their Figure 3). Figure 4 omits the values of those animals which had reached criterion.

During acquisition, the cats and mice committed

Table 1

Comparison of All 28 Cats, 14 Guinea Pigs, and 14 Mice in Delayed Alternation Acquisition and in Delayed Alternation Relearning

\begin{tabular}{|c|c|c|c|c|}
\hline \multirow[b]{2}{*}{ Comparison } & \multicolumn{4}{|c|}{ Level of Significance } \\
\hline & $C-G$ & M-G & $\mathrm{M}-\mathrm{C}$ & Combined \\
\hline 1. Number of $T$ to criterion (ACQ; $K, M$ ) & .001 & n.s. & .05 & .001 \\
\hline 2. Number of E/T to criterion $(\mathrm{ACQ} ; \mathrm{K}, \mathrm{M})$ & .001 & .001 & n.s. & .001 \\
\hline 3. Initial level of correct performance (ACQ; $K, M$ ) & .001 & .01 & n.s. & .001 \\
\hline 4. Number of $\mathrm{E} / \mathrm{T}$ to criterion $(\mathrm{REL} ; \mathrm{K}, \mathrm{M}$ ) & .01 & .05 & n.s. & .05 \\
\hline 5. Consistency coefficients $(A C Q ; S)$ & .001 & .01 & n.s. & \\
\hline 6. Consistency coefficients (REL;S) & .01 & .01 & .01 & \\
\hline 7. Correlation of $T$ to criterion during ACQ with saving scores (S) & .01 & n.s. & n.s. & \\
\hline 8. Number of initial $\mathrm{E} /$ number of all $\mathrm{E}(\mathrm{ACQ} ; \mathrm{K}, \mathrm{M})$ & .05 & .01 & n.s. & .001 \\
\hline 9. Number of perseverative $\mathrm{E} /$ number of all $\mathrm{E}(\mathrm{ACQ} ; \mathrm{K}, \mathrm{M})$ & .05 & .01 & n.s. & .001 \\
\hline $\begin{array}{l}\text { 10. Number of sessions in which perseverative } E \text { occurred/ } \\
\text { total number of sessions to criterion }(A C Q ; K, M)\end{array}$ & .01 & n.s. & n.s. & .05 \\
\hline
\end{tabular}

Note $-A C Q=$ acquisition, $R E L=$ relearning; $T=$ trials, $E=$ errors, $C=$ cats, $G=$ guinea pigs, $M=$ mice. Tests used were Kruskal - Wallis one-way analysis of variance $(K)$, Mann-Whitney $U$ test $(M)$, and Spearman rank-correlation coefficient $(S)$. For levels of significance, $p$ is less than the value given; n.s. indicates $p>.05$. 


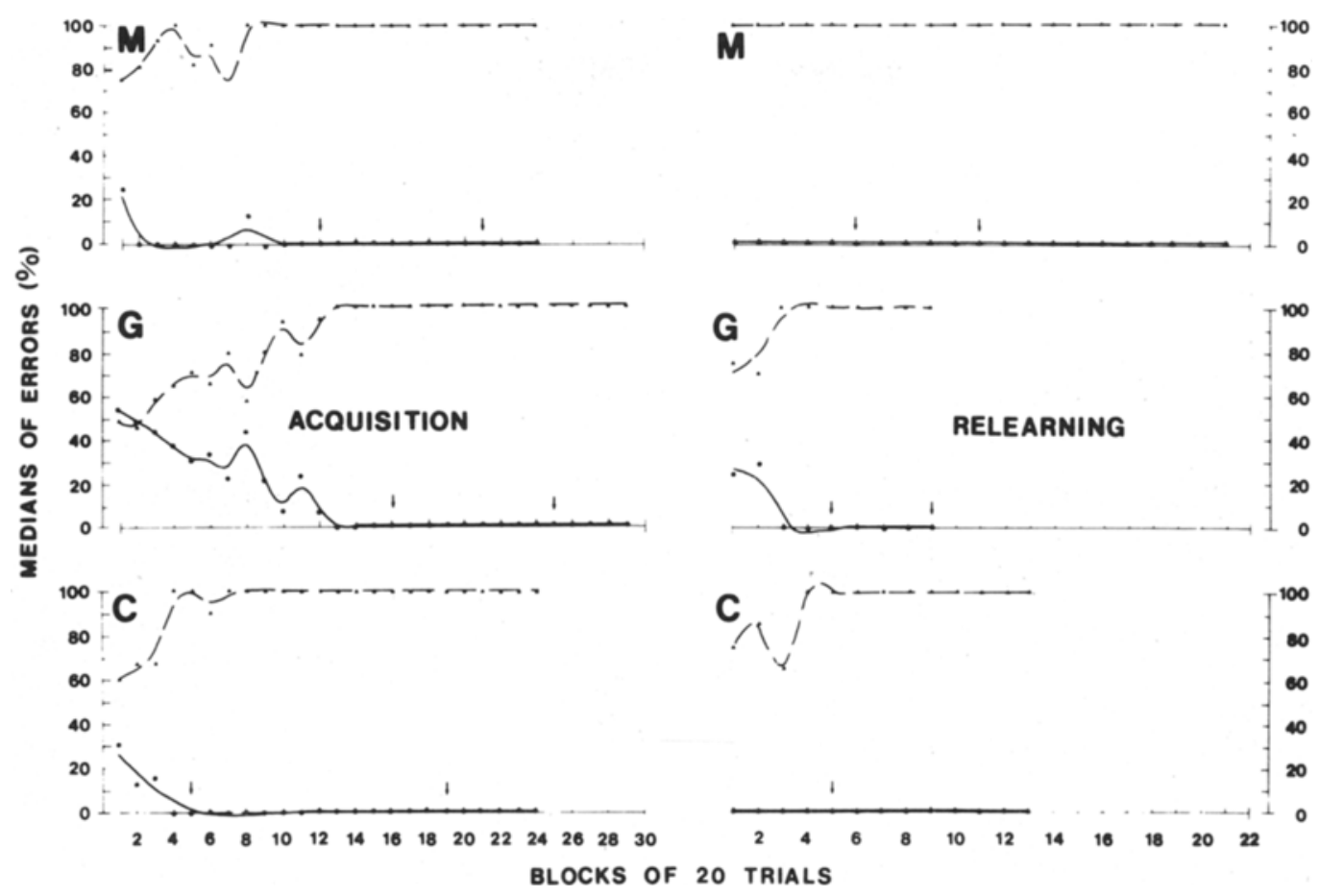

Figure 3. Medians of initial errors (triangles, broken lines) and of perseveration errors (dots, continuous lines) for mice (M), guinea pigs (G), and cats (C) during both phases of delayed alternation learning. The computation of the curves follows that used in Figure 1; that is, the median value of the three criterion sessions is included in the curve for each animal that had gained criterion. The arrows are as in Figure 1.

significantly more initial errors than the guinea pigs (comparison 8). Complementary results were obtained in the portion of perseverative errors relative to all performed errors during delayed alternation acquisition: here the guinea pigs committed significantly more perseveration errors than did the cats and mice (comparison 9). No significant differences were found during relearning in either of these measures.

Because these values may be confounded with the percentage of animals in each group having already gained criterion, a further interspecies analysis was done both for the acquisition phase and for the relearning phase: for each species, the number of sessions in which perseverative errors occurred was divided by the total number of sessions to criterion. This measure revealed significant overall differences during delayed alternation acquisition due mainly to the small ratio obtained in the cats (comparison 10). During relearning, differences were nonsignificant in both three- and two-species comparisons.

Figure 4 reveals that during delayed alternation acquisition most of the cats and guinea pigs committed perseveration errors during most of the sessions until reaching criterion (cats: during 14 of 24 sessions, $58 \%$ of the sessions: guinea pigs: during 22 of 29 sessions, $76 \%$ of the sessions). Most of the mice did not make perseveration errors (only during 5 of 24 sessions, $21 \%$ of the sessions). This relationship between species is accentuated when one con- siders only the sessions needed for the first half of the animals of each species to reach criterion (cats: $4 / 5=80 \%$; guinea pigs: $14 / 15=93 \%$; mice: $2 / 12=17 \%$ ) .

These differences in number of medians of performed perseveration errors between species disappeared during relearning (first value $=$ number of ses sions with perseveration errors divided by all sessions until the last animal of a given species had gained criterion; second value $=$ number of sessions with perseveration errors divided by number of sessions until half of the animals had reached criterion-cats: $4 / 13=31 \%, 0 / 4=0 \%$; guinea pigs: $2 / 9=22 \%, 2 / 5=$ $40 \%$; mice: $5 / 21=24 \%, 0 / 4=0 \%$ ).

The relearning curves of Figure 4, which show the medians of perseveration errors, appear to be complementary for guinea pigs, on the one hand, and cats and mice, on the other: Median values of perseveration errors obtained for the first half of the cats and mice to reach criterion were zero, while median values for those cats and mice that reached criterion on the second half were in part above zero. Conversely, median values for the guinea pigs that reached criterion during the first half were partly above zero, while median values observed for the guinea pigs that reached criterion during the second half were zero.

Figures 2 and 4 demonstrate, furthermore, that at least half of the animals of each species needed four 

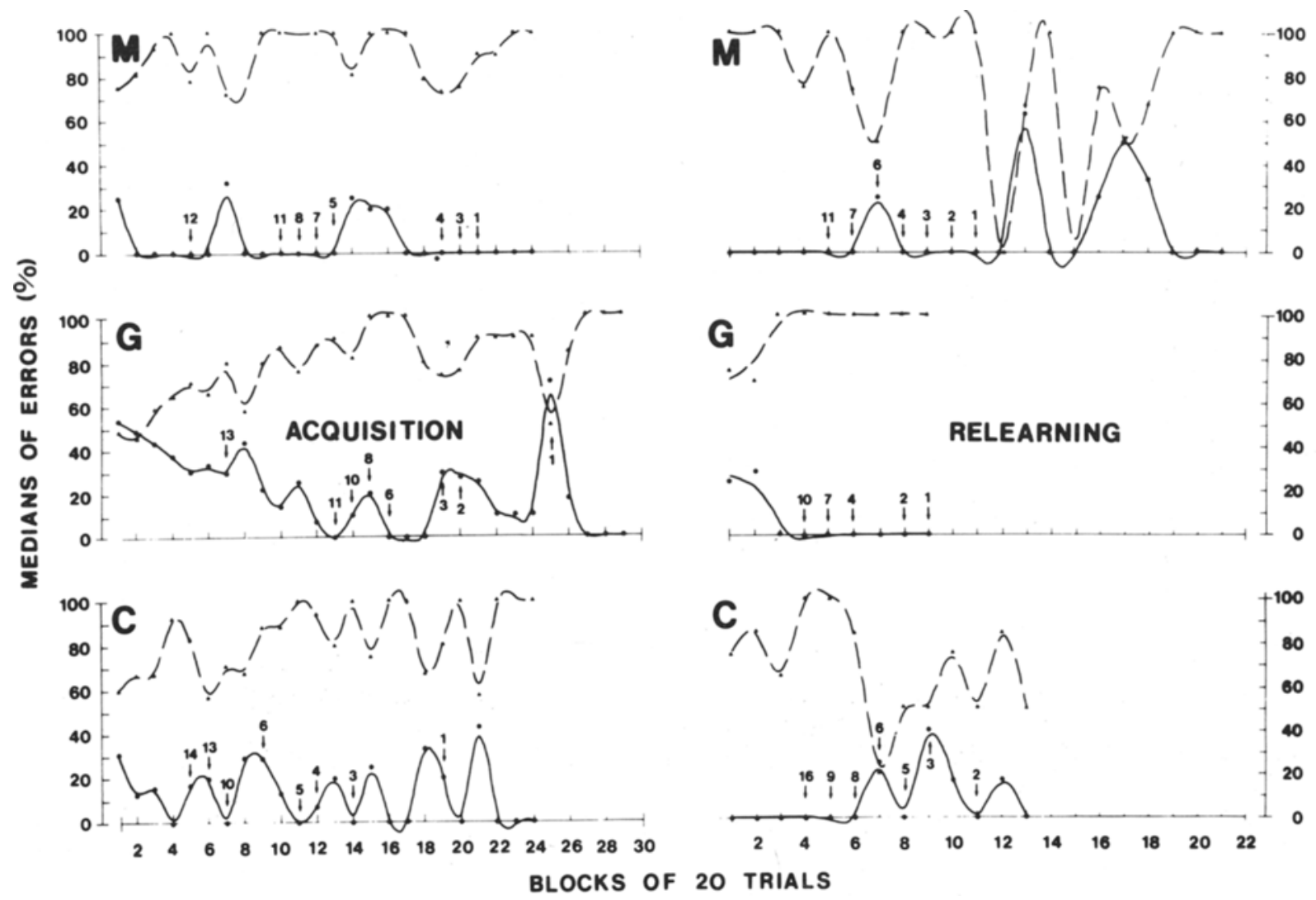

Figure 4. Medians of initial errors (triangles, broken lines) and of perseveration errors (dots, continuous lines) for mice (M), guinea pigs (G), and cats $(C)$ during both phases of delayed alternation learning. Unlike the computations of the curves in Figure 3, the present curves omit the values of each animal after it had gained criterion. Numbered arrows represent the number of animals that are included in the curve from the sessions, marked by the arrow, onwards.

sessions only to regain criterion following the 10-day retention interval (that is one more than the minimum number of three sessions).

\section{DISCUSSION}

Our analysis of delayed alternation learning in cats, mice, and guinea pigs revealed that (a) animals of all three species can acquire delayed alternation within similar time spans, (b) there is considerable variance in the performance of individual animals independent of their species, (c) guinea pigs as a group appear to need a somewhat longer time to acquire delayed alternation than do mice and cats, and (d) relearning of delayed alternation after a 10day retention interval seems to follow similar laws in all three species.

While these are the main conclusions of our analysis, we shall compare the present behavioral situation with similar learning situations and interpret possible commonalities and differences in delayed alternation performance among the three species.

Contrary to other forms of spatial delayed-response tasks (delayed response, double-delayed alternation), delayed alternation tasks have been used infrequently with cats and have, to our knowledge, never been used with guinea pigs or mice. The present testing situation, using a large maze with several turns in the same direction per trial, appears to represent a favorable learning situation when compared with other testing forms for delayed alternation learning (Nencki Testing Situation: Divac, 1974; Wisconsin General Test Apparatus: Yamaguchi, Warren, \& Hara, 1963). Markowitsch and Pritzel (1978) have compared the delayed alternation performance of cats tested in a box with minimized spatial and kinesthetic cues with the performance of cats tested in the presently used maze. They reported about 10fold differences in acquisition time between cats tested in the two situations. Furthermore, as in the present study, cats tested in a modified T-maze started with an initial level of about $75 \%$ correct responses, whereas cats in the restricted leverpress situation started at chance level $(50 \%)$. It appears that the shaping phase alone (in which the present situation is shorter than it was in the leverpress situation) was sufficient to raise the cats' average performance to above-change level.

Analysis of our results with respect to situations or variables for which one species differed significantly 
from another reveals that for all two-species comparisons one or more significant differences were observed, with the exception that cats were never significantly inferior to mice. A further general observation was that more interspecies differences were found during the acquisition phase than during relearning and that, during acquisition, guinea pigs were most consistently inferior when compared with cats and mice.

During relearning, most of the interspecies differences observed during the acquisition phase disappeared. At the initial level of correct responses, guinea pigs remained inferior to cats, and for the number of errors/trials, guinea pigs remained inferior to both cats and mice.

On the other hand, guinea pigs were, as a group, faster than cats and mice in the number of sessions required for the last animal to regain criterion following the 10-day retention interval, and guinea pigs were the only species in which all animals acquired positive saving scores. Furthermore, the average consistency coefficient (median of acquisition and relearning phase) was highest for the guinea pigs, and the difference in the correlation values of the consistency coefficients of both phases was lowest in guinea pigs.

In spite of these interspecies differences, it should be noted that none of the three species was consistently inferior or superior to another. Instead, several measures of performance during relearning revealed similarities in the behavior of all three species.

It appears that the three species may have needed different lengths of time to adapt to the situation and to find strategies to manage the learning problem, but that following this initial phase the great majority of animals of all three species memorized the task successfully after the 10-day break. We can, therefore, conclude that species-specific or species-typical adaptations influenced the acquisition of delayed alternation in our three species to different extents, but that, in spite of this difference, animals of all three species have a rather similar ability to behave properly in a delayed alternation paradigm.

Comparison of learning and performance of different species is complicated by a number of variables. The present study included species that varied both in specific adaptation to the environment and in affiliation to different taxonomic orders. In order to reach more precise conclusions with respect to the learning capacity of different species, not only should their behaviors be determined for a number of tests and testing situations of a given category (Warren, 1974), but also their individual phylogenetic origin and their specific biological predispositions should be considered and compared separately (Hodos, 1970; Hodos \& Campbell, 1969).

A "human lineage" "which would give some clue to patterns of evolution"' (Hodos \& Campbell, 1969, p. 341) could, for example, consist of bush babies, rhesus monkeys, chimpanzees, and human beings. In a comparison that is based primarily on the ecological background, the behavior of a colony of different species of birds, living together along the seashore, might be considered together. Also, a priori, restricted comparisons of interspecies behavior might provide more detailed and more relevant insights into mechanisms and capabilities of individual species than do comparisons in which these variables are intermingled.

\section{REFERENCES}

Beadle, M. The cat. London: Collins \& Harvill, 1977.

Bitterman, M. E. The comparative analysis of learning. Science, 1975, 188, 699-709.

BroокshiRe, K. H. Comparative psychology of learning. In M. H. Marx (Ed.), Learning: Interactions. New York: Macmillan, 1970.

Denny, M. R., \& Ratner, S. C. Comparative psychology Homewood, I1l: Dorsey Press, 1970.

Divac, I. Caudate nucleus and relearning of delayed alternations in cats. Physiological Psychology, 1974, 2, 104-106.

Fletcher, H. J. The delayed response problem. In A. M. Schrier, H. F. Harlow, \& F. Stollnitz (Eds.), Behavior of nonhuman primates (Vol. 1). New York: Academic Press, 1965.

Glickman, S. E., \& Hartz, K. E. Exploratory behavior in several species of rodents. Journal of Comparative and Physiological Psychology, 1964, 58, 101-104.

Hal,E, E. B. Comparative behaviour. In E. S. E. Hafez (Ed.), The behaviour of domestic animals. London: Baillière, Tindall \& Cox, 1962

Harper, L. V. Behavior. In J. E. Wagner \& P. J. Manning (Eds.), The biology of the guinea pig. New York: Academic Press, 1976.

HERSCHEL, J. A scale ratio of body weight to brain weight as a comparative index for relative importance of brain size in mammals of widely varying body mass. Psychological Reports, 1972, 31, 84-86.

HILGARD, E. R. A summary and evaluation of alternative procedures for the construction of Vincent curves. Psychological Bulletin, 1938, 35, 282-297.

Honos, W. Evolutionary interpretation of neural and behavioral studies of living vertebrates. In F. O. Schmitt (Ed.), The neurosciences: Second study program. New York: Rockefeller University Press, 1970.

Hodos, W., \& Campbril, C. B. G. Scala naturae: Why there is no theory in comparative psychology. Psychological Review, $1969,76,337-350$

Hun't:R, W. S. The temporal maze and kinaesthetic sensory processes in the white rat. Psychobiology, 1920, 2, 1-17.

IVERSEN, S. D., \& Weiskrantz, L. The acquisition of conditional discriminations in baboons following temporal and frontal lesions. Experimental Neurology, 1967, 19, 78-91.

Jonson, K. M., Lyle, J. G., Edwards, M. J., \& Penny, R. H. C. Problems in behavioural research with the guinea pig: A selective review. Animal Behaviour, 1975, 23, 632-639.

Kummer, H. Beitrag zur quantitativen Bestimmung der Entwicklungshöhe des Säugetiergehirnes. Psychiatria et Neurologia, $1961,142,352-375$

Kunkel, P., \& Kunkfi, I. Beiträge zur Ethologie des Hausmeerschweinchens Cavia aperea f. porcellus (L.). Zeitschrift für Tierpsychologie, 1964, 21, 602-641.

LAWICKA, W. Physiological mechanisms of delayed reactions. 11. Delaved reactions in dogs and cats to directional stimuli. Acta Bioloyiac Experimentalis, 1959, 19, 199-220. 
LAWICKA, W., \& Konorski, J. The effects of prefrontal lobectomies on the delayed responses in cats. Acta Biologiae Experimentalis, 1961, 21, 141-156.

LеICHт, W. H. Ethologie einheimischer Säugetiere: Tiere der offenen Kulturlandschaft (Part 2) Feldhamster, Feldmaus. Heidelberg: Quelle \& Meyer, 1979.

Llonard, C., Schneider, G. E., \& Gross, C. G. Performance on learning set and delayed-response tasks by tree shrews (Tupaia glis). Journal of Comparative and Physiological Psychology, 1966, 62, 501.504.

Levine, M. S., Hull, C. D., Buchwald, N. A., \& Villablanca, J. R. Effects of caudate nuclei or frontal cortical ablations in kittens: Motor activity and visual discrimination performance in neonatal and juvenile kittens. Experimental Neurology, 1978, 62, 555-569.

Livesey, P. J. A note on double alternation by rabbits. Journal of Comparative and Physiological Psychology, 1964, 57, 104-107.

LIVESEY, P. J. Comparison of double alternation performance of white rats, rabbits, and cats. Journal of Comparative and Physiological Psychology, 1965, 59, 155-1 58.

Livesey, P. J. Double- and single-alternation learning by rhesus monkeys. Journal of Comparative and Physiological Psychology, 1969, 67, 526-530.

Livesey, P. J. Critique and comment: A consideration of the neural basis of intelligent behavior: Comparative studies. Behavioral Science, 1970, 15, 164-170.

Livesey, P. J., \& LitTle, A. Sequential learning by children. Journal of Genetic Psychology, 1971, 118, 33-38.

LockARD, R. B. Reflections on the fall of Comparative psychology: Is there a message for us all? American Psychologist, 1971, 26, 168-179.

Maier, R. A., \& Maier, B. M. Comparative animal behavior. Belmont, Calif: Brooks/Cole, 1970.

Marascuilo, L. A., \& McSweeney, M. Nonparametric and distribution-free methods for the social sciences. Monterey, Calif: Brooks/Cole, 1977.

Markowitsch, H. J., \& Pritzel, M. Delayed alternation learning in cats: Implications for the interpretation of prefrontal symptoms. Acta Neurobiologiae Experimentalis, 1978, 38, 215-222.

Markowitsch, H. J., Pritzel, M., Kessler, J., Guldin, W., \& FreEMAN, R. B., JR. Delayed-alternation performance after selective lesions within the prefrontal cortex of the cat. Behavioural Brain Research, 1980, 1, 67-91.
Nigrosh, B. J., Slotnick, B. M., \& Nevin, J. A. Olfactory discrimination, reversal learning, and stimulus control in rats. Journal of Comparative and Physiological Psychology, 1975, 89, 285-294.

REINSCH, C. H. Smoothing by spline functions. Numerische Mathematik, 1967, 10, 177-183.

Riddell, W., Corl, K., Bennett, V. D., \& Reimers, R. O. Discrimination learning differences and similarities as a function of brain index. Physiology \& Behavior, 1974, 13, 401-405.

Siegel, S. Nonparametric statistics. New York: McGraw-Hill, 1956.

STAmm, J. S. Dorsolateral frontal ablations and response processes in monkeys. Journal of Comparative and Physiological Psychology, 1970, 70, 437-447.

Warren, J. M. The comparative psychology of learning. Annual Review of Psychology, 1965, 16, 95-118.

Warren, J. M. Evolution, behavior and the prefrontal cortex. Acta Neurobiologiae Experimentalis, 1972, 32, 581-593.

WARREN, J. M. Learning in vertebrates. In D. A. Dewsbury \& D. A. Rethlingshafer (Eds.), Comparative psychology: $A$ modern survey. New York: McGraw-Hill, 1973.

Warren, J. M. Possibly unique characteristics of learning by primates. Journal of Human Evolution, 1974, 3, 445-454.

Weiskrantz, L. Memory. In L. Weiskrantz (Ed.), Analysis of behavioral change. New York: Harper \& Row, 1968.

Yamaguchi, S., \& Warren, J. M. Single versus double alternation learning by cats. Journal of Comparative and Physiological Psychology, 1961, 54, 533-538.

Yamaguchi, S., Warren, J. M., \& Hara, K. Alternation and delayed alternation by cats with premotor lesions. Journal of Comparative and Physiological Psychology, 1963, 56, 824-828.

YARB ROUGH, J. U. Delayed reaction with sound and lights in cats. Journal of Animal Behavior, 1917, 7, 87-110.

\section{NOTE}

1. As it turned out, the number of sessions to criterion during delayed alternation acquisition would have differed for only 2 of the 14 mice, and during relearning for only 1 , if the criteria used had been the same as those used with the other two species.

(Received for publication November 27, 1979; revision accepted March 3, 1980.) 